\title{
The Empirical Research of Aerobic Endurance Training in Football
}

\author{
Weiping Xie, Yang Geng \\ Pingxiang University, Pingxiang, Jiangxi, 337055, China
}

Keywords: Football sport, aerobic endurance, empirical research, college students

\begin{abstract}
With the rapid development of our social economy, the competition between countries not only covers aspects of the economic and politic and so on, but also covers the culture, sports, education and so on. Along with our country education system reforming and the deepening of the new curriculum reform and development, people are paying more and more attention to the quality education of college students, to promote college students to get all-round development in morality, intelligence and physique.Related research results show that college students' aerobic endurance training in football training has been popularized and applied gradually, and has played a good result.But the current reality is that our country university students in the process of aerobic training method is simple, and is lack of a systematic, scientific and rigor, in a certain extent, there is no accurate grasp and there exist the special characteristics of soccer program, and the knowledge of how to control the football aerobic training and technical know too little.This paper made a detailed empirical research to this, and it has the certain model function to our country university student soccer the aerobic endurance training of training.
\end{abstract}

\section{Introduction}

Aerobic endurance is one of the most basic body ability of sports fitness, and it can ensure the athletes' body under the condition of high strength, high against movement quality and also it is the ability to work for a long time[1].Aerobic endurance training is also an integral part of football player physical ability training. The essential characteristics of modern football match determines the soccer movement the special physical ability must be combined with a very, not with tactical purpose physical performance characteristics with football "special" run counter to the nature of the physical features [2].

At this stage, no ball state of aerobic training on the football still occupied large proportion of the special physical training, the long run, trail running, running speed, intermittent running training with coaches at all levels of aerobic endurance training program.In specific training period and the stage of training, no ball aerobic endurance training for the athletes' physical reserves also lay a good foundation, but often use constant of the aerobic stamina training not using basketball, can make the football player special form of muscle contraction, the motor unit recruitment methods, muscle fiber type and energy metabolism and function form, technique and rhythm of running to produce a series of morphology and physiological and biochemical characteristics, such as adaptive change.And this kind of adaptive changes such as a sharp turn in the football match, abrupt stop, interception, jumping, change to the outbreak of key technologies, such as hard links such as has a bad influence [3-5].

Foreign related research also confirmed that combined with aerobic ability training of football player special athletic performance has many positive effects [6-10].Get oxygen transport capacity of athletes, the ability to pump the blood of the heart, vo2 Max, running from the game, the sprint frequency and number of the ball has been improved obviously.And thus put forward the judgment of maximum heart rate field test method [11], for the coaches to effectively control training provides a good guidance.

Based on this, combining previous research results, this study designed the special ball aerobic endurance training method and its practice effect was certificated with the experiments, the test under 
different training control elements with the ball exercises influence on changes in the body load, special physical training aimed at our country soccer movement the scientific design to provide the reference.

\section{The research object and methods}

Select college football player, a total of 12, including four athletes, five secondary athletes, athlete, three athletes aged between 20 to 23, the average age was $(21.26+1.53)$, between training duration of $7 \sim 12$ years, the average training fixed number of year is $(9.35+2.01)$ years, between $168 \sim 185 \mathrm{~cm}$ height, average height (175.68-1.83) cm, $60 \sim 75 \mathrm{~kg}$ weight, average weight for $66.92+/-2.04 \mathrm{~kg}$, quiet heart rate $48 \sim 65$ times/min, the average quiet heart rate was $(65.45+1.34)$ times $/ \mathrm{min}$, see table 1 and table 2.

Table1.The training principle and intensity of soccer aerobic endurance

\begin{tabular}{|c|c|c|}
\hline The intensity of load & Mean (\% of HR max) & Range (\% of HR max) \\
\hline Aerobic low intensity & 65 & $70-80$ \\
\hline In the aerobic strength & 80 & $80-100$ \\
\hline Aerobic high strength & 90 & \\
\hline
\end{tabular}

Table2.Subject's basic information

\begin{tabular}{|c|c|c|c|c|c|c|}
\hline Name & Birthday & Level & Year/a & Length/cm & Weight/kg & Heart rate/min \\
\hline Duan ** & 1993 & 2 & 9 & 180 & 70 & 57 \\
\hline Gong** & 1994 & 2 & 8 & 178 & 62 & 58 \\
\hline Zheng ** & 1996 & 2 & 9 & 183 & 76 & 61 \\
\hline Zhang** & 1990 & 1 & 10 & 182 & 75 & 65 \\
\hline $\mathrm{Lu}^{* *}$ & 1992 & 1 & 7 & 185 & 75 & 64 \\
\hline $\mathrm{Xu} * *$ & 1993 & 2 & 8 & 175 & 74 & 47 \\
\hline Wang $* *$ & 1995 & 1 & 12 & 178 & 75 & 60 \\
\hline Chen ** & 1995 & 2 & 9 & 184 & 75 & 58 \\
\hline Gao ** & 1996 & 1 & 13 & 180 & 65 & 61 \\
\hline Huang* & 1993 & 1 & 9 & 179 & 75 & 59 \\
\hline
\end{tabular}

Aerobic endurance is a soccer player, one of the must have ability to match the outcome of the key factors and the level of aerobic endurance has very big connection.Football matches the essence of its own characteristics of football player physical ability have very high requirements.However, we found that most of the state are aerobic training without the ball.Long runs, trail running, running speed and so on with the coaches at all levels of aerobic endurance training program.But in the case of out of football, aerobic endurance training for college students' football player don't able to meet their needs.Heart rate is an important manifestation of aerobic endurance training results, because of the different athletes physical quality, there exists a corresponding difference, the value of heart rate, so on college students' football players to detect aerobic endurance training heart rate test is a best way.

\section{Heart rate test}

Heart rate test in the choice of site is in the standard football field, see figure 1 . When the players after the warm-up before test, each players from every $15 \mathrm{~s}$ at seven o 'clock, the front four laps with constant speed in the run, and to ensure that each lap is done in the $90 \mathrm{~s}$, on the fifth lap with a high speed run, ensure the completion in the $60 \mathrm{~s}$, the sixth circle, the first half of the circle must be made within the $20 \mathrm{~s}$, after half a circle is to use the fastest speed to complete. 


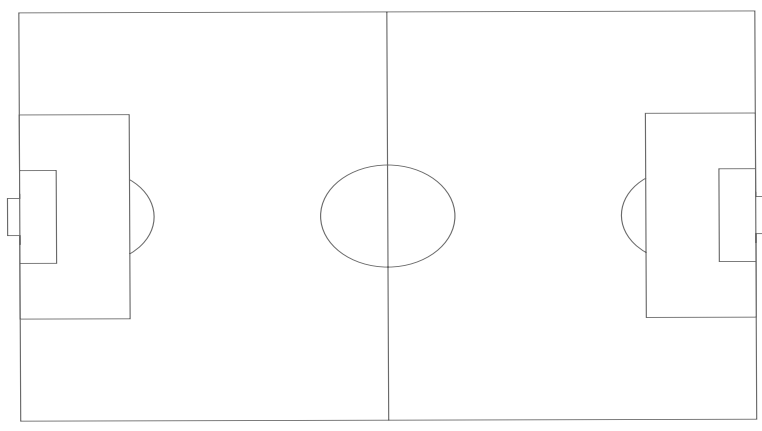

Figure 1.Maximum heart rate test site

\section{The 4v2 mobile control practice}

Firstly, we set the score elements. In the test number arrangement: 12 people can be divided into two groups, each group of 6 people, the choice of venue: $5 \mathrm{~m} \times 5 \mathrm{~m}$.Each group 1 ball, outside the square test site arrangement in the ball, four players, in the middle of the defenders can work together to cut rob of football, in the process of sectional rob football athletes may not be lifted, the relationship between must be hand in hand, when the ball players need to move in after successful completion of a work.If in the process of passing football was robbed by the middle of the defender is successful, then it is the ball players and defensive players exchange position.Ball players passing success 20 times, just remember 1 minute, then the number that middle defense players practice time is 6 minutes, practice repeating group for 1 set, the last recorded heart rate.

Secondly, we don't set the score. In accordance with set scoring elements in all conditions, but not increase the score, just six minutes mobile pass practice, heart rate and statistics.

\section{6v6 defensive practice base score}

Firstly, we change the score elements. In the test number arrangement: 12 people can be divided into two groups, each group of 6 people, the choice of venue: a third of the football field.Six people in the scope of a group of $6 \mathrm{v} 6$ small game, each team's defensive players to put in his own half barrels, every place a 1 meter.Want to score requires an offensive player must play a foot down the other site of logo barrels, when players knocking each other marks barrels will knock down after scoring barrels back to your own site.Will continue to play at the same time, the rest of the other players, allowing players are free to choose where, after the end of the game, most sent to markers of one party win.Practice time is 6 minutes, repeat group number is 1 .

Secondly, we don't change the score elements.In accordance with change score elements in all conditions.But after down markers, immediately the centralizer, not back to their own site, continue the game.Practice time is 6 minutes, repeat group number is 1 .

\section{The results of the study}

\section{Load intensity and change in groups of $\mathbf{4} \mathbf{v} \mathbf{2}$ mobile control practice}

As can be seen in table 3, 50\% in the test $2-80 \%$ of total load intensity of $98.62 \% .50 \%$ of test 3-80\% of total load intensity of 98.68\%.Test 1 and test 2 percentage $70 \% 79 \%$ strength in practice has the highest percentage of the total load of each group, respectively, 50. 44\% and 54. 31\%.Among them, the test 1 and test 2 from 50\% to 59\%, 70\% and 79\% exist significant differences in the intensity of percentage, test 2 on the overall load strength slightly higher than the test 1 , and the average heart rate test 2 and maximum heart rate were higher than the test 1 .

\section{Load intensity and change in groups of $6 \mathrm{v} 6$ practice base scoring}

Test results showed that due to expand the scope of the field in the test, the load strength has improved, the arrangement of the test set up in a certain number of attacking target, will be the athletes' score difficulty is reduced, therefore, no more than $90 \%$ of the total load intensity.And without changing elements test and change the score test scores in the 70-79 and 80-79 strength percentage and average heart rate maximum heart rate exist significant difference.Don't change test score elements on the strength of 70-80 percent more than change test score elements, while change factor test score in the strength of $80-90$ percent more than test scores elements shall not be 
changed.On the change of the average heart rate and maximum heart rate, change elements test score were higher than do not change test score elements, as shown in the table 4.

Table3.The intensity and paired sample T test of exercise 1 and exercise 2

\begin{tabular}{|c|c|c|c|}
\hline The intensity of load & Exercise 1 & Exercise 2 & P Value \\
\hline $\begin{array}{c}50 \%-59 \% \text { (The intensity of } \\
\text { the percentage) }\end{array}$ & $12.56 \pm 2.83$ & $4.18 \pm 3.79$ & $0.016^{* *}$ \\
\hline $\begin{array}{c}60 \%-69 \% \text { (The intensity of } \\
\text { the percentage) }\end{array}$ & $35.62 \pm 7.83$ & $40.19 \pm 4.60$ & $0.318^{*}$ \\
\hline $\begin{array}{c}70 \%-79 \% \text { (The intensity of } \\
\text { the percentage) }\end{array}$ & $50.44 \pm 6.04$ & $54.31 \pm 5.84$ & 0.224 \\
\hline Average heart rate & $132.3 \pm 5.02$ & $134.6 \pm 5.72$ & 0.191 \\
\hline Maximum heart rate & $145.7 \pm 3.69$ & $148.3 \pm 4.16$ & \\
\hline
\end{tabular}

Table4.The intensity and paired sample $\mathrm{T}$ test of exercise1 and exercise2

\begin{tabular}{|c|c|c|c|}
\hline $\begin{array}{c}\text { The intensity of } \\
\text { load(Percentage) }\end{array}$ & Exercise 1 & Exercise 2 & P Value \\
\hline $60-69$ & $5.01 \pm 1.99$ & $3.98 \pm 3.24$ & 0.398 \\
\hline $70-79$ & $49.01 \pm 3.22$ & $42.34 \pm 5.01$ & 0.033 \\
\hline $80-89$ & $45.98 \pm 7.32$ & $53.87 \pm 7.29$ & 0.011 \\
\hline Average heart rate & $146.8 \pm 3.87$ & $153.3 \pm 4.84$ & 0.042 \\
\hline Maximum heart rate & $161.2 \pm 4.37$ & $164.8 \pm 5.44$ & 0.039 \\
\hline
\end{tabular}

\section{Summary}

1) Under the precondition of different training control elements, moving mass control exerciseaffects body load intensity

Commonly used technical training will be a football match design of the ball, passing, dribbling, possession of special fusion among the college students' football training of aerobic endurance training, to ensure that as much as possible to ensure football training form and soccer practice form the basic rule of match, combined with the practical skills at the same time, cultivate athletes can better use of technology, reasonable use technology to improve the overall effect of the special physical training.Due to the requirements in the actual test between defensive player to be hand in hand the training, so that in a certain extent, limits the athlete movement speed and response sensitivity, can effectively avoid appear the phenomenon of excessive load intensity in the process of training.Overall experimental results show that the difference between two groups of training load intensity and heart rate, the key reason is that the whole process of test set score, because in the training set the scoring elements will be trained to become more competitive, the number of team members with a score increased significantly, and smoothly pass through successful after the frequent change of edge, effectively promoted the defender's enthusiasm and attention, which is set grading factors test test load strength slightly higher than the set not scoring elements in one of the reasons.For college athletes average heart rate and maximum heart rate test results showed that no set test test scores and set up the test score element content is fit for aerobic low intensity endurance training.

2) In different training under the premise of control elements, the impacts strike home scoring defense exercise to body load intensity

The results show that the differences in two groups of training load is mainly comes from the training score elements in change.Change score elements tests, a key marker score factors significantly improved the overall running of the players, in the whole training process, the athletes through active mobile and scoop out the hope of getting a better position to hit the ball, and then get the iconic score.Compared with previous training found, along with training elements, elements in 
the change of test between athletes in the consciousness of active to cooperate will greatly improve, to a certain extent, can effectively enhance the overall intensity in training load.So, set up the design of the test score elements content more in line with the college students' football aerobic moderate intensity endurance training.

\section{References}

[1] Azam Z, Zaki S, Sariman H, et al. Effects of Periodized Small-Sided Training on Physical Fitness Performance Among Young Male Football Players[C].Proceedings of the 2nd International Colloquium on Sports Science, Exercise, Engineering and Technology 2015 (ICoSSEET 2015). Springer Singapore, 2016: 79-88.

[2] Botonis P G, Toubekis A G, Platanou T I. Concurrent strength and interval endurance training in elite water polo players[J]. The Journal of Strength \& Conditioning Research, 2016, 30(1): 126-133.

[3] Cunha G D S, Vaz M A, Geremia J M, et al. Maturity status does not exert effects on aerobic fitness in soccer players after appropriate normalization for body size[J]. Pediatric exercise science, 2016, 28(3): 456-465.

[4] Requena B, García I, Suárez-Arrones L, et al. Off-Season Effects on Functional Performance, Body Composition, and Blood Parameters in Top-Level Professional Soccer Players[J]. The Journal of Strength \& Conditioning Research, 2017, 31(4): 939-946.

[5] Mohr M, Krustrup P. Comparison between two types of anaerobic speed endurance training in competitive soccer players[J]. Journal of Human Kinetics, 2016, 51(1): 183-192.

[6] Stevens T G A, de Ruiter C J, Twisk J W R, et al. Quantification of in-season training load relative to match load in professional Dutch Eredivisie football players[J]. Science and Medicine in Football, 2017: 1-9.

[7] Castagna C. 4 Soccer referee training and performance[C].Science and Football VIII: The Proceedings of the Eighth World Congress on Science and Football. Taylor \& Francis, 2016: 40.

[8] Fyfe J J, Bartlett J D, Hanson E D, et al. Endurance Training Intensity Does Not Mediate Interference to Maximal Lower-Body Strength Gain during Short-Term Concurrent Training[J]. Frontiers in Physiology, 2016, 7.

[9] Zhang J, Zhang Y. A Study on the Protective Function on Skeletal Muscle Mitochondria due to Aerobic Endurance Training[J]. International Journal of Simulation--Systems, Science \& Technology, 2016, 17(45).

[10]Chan H C K, Fong D T P, Lee J W Y, et al. Power and endurance in Hong Kong professional football players[J]. Asia-Pacific Journal of Sports Medicine, Arthroscopy, Rehabilitation and Technology, 2016, 5: 1-5.

[11] Manouvrier C, Cassirame J, Ahmaidi S. Proposal for a Specific Aerobic Test for Football Players: The "Footeval”[J]. Journal of Sports Science \& Medicine, 2016, 15(4): 670.

[12] Yanci J, Castagna C, Los Arcos A, et al. Muscle strength and anaerobic performance in football players with cerebral palsy[J]. Disability and health journal, 2016, 9(2): 313-319.

[13]Ramírez-Campillo R, González-Jurado J A, Martínez C, et al. Effects of plyometric training and creatine supplementation on maximal-intensity exercise and endurance in female soccer players[J]. Journal of Science and Medicine in Sport, 2016, 19(8): 682-687. 